\title{
ANÁLISE DAS POLÍTICAS DE APOIO A ARRANJOS PRODUTIVOS LOCAIS NOS ESTADOS DO CENTRO-SUL DO BRASIL
}

\author{
Ana Lúcia Tatsch \\ Universidade do Vale do Rio dos Sinos (UNISINOS)/Universidade Federal do Rio de Janeiro (UFRJ) \\ Marisa dos Reis A. Botelho \\ Universidade Federal de Uberlândia (UFU)/Universidade Federal do Rio de Janeiro (UFRJ)
}

\begin{abstract}
ANÁLISE DAS POLÍTICAS DE APOIO A ARRANJOS PRODUTIVOS LOCAIS NOS ESTADOS DO CENTRO-SUL DO BRASIL

Resumo: Entre o final dos anos 1990 e o início dos anos 2000, a partir de caminhos próprios ou sob influência das políticas em nível federal, os estados brasileiros dão início às suas políticas de apoio à APLs. A análise de como estas políticas foram implementadas nos estados do Centro-Sul do Brasil é o objetivo principal deste artigo que, analisa, também, os critérios norteadores da seleção dos arranjos focalizados pelas políticas, assim como o escopo, institucionalidade e instrumentos mobilizados para levar a cabo o apoio aos APLs. Ressalta que as principais tipologias para os APLs, cujo foco são os objetivos de política, constituem-se em referencial analítico para avaliar como vem se desenvolvendo o processo de implementação dessas políticas em alguns estados brasileiros. A avaliação empreendida neste trabalho traz, como conclusão principal, uma significativa diversidade nas políticas estaduais de apoio à APLs.
\end{abstract}

Palavras-chave: Arranjos produtivos locais, políticas públicas.

\section{ANALYSIS OF SUPPORT LOCAL ARRANGEMENTS PRODUCTIVE POLICIES ON CENTRAL-SOUTH STATES IN BRAZIL}

Abstract: Between the late 1990s and early 2000s, from their own paths or under the influence of central government policies, the Brazilian states initiate their policies to support clusters. The analysis of how these policies were implemented in the states of South-Central Brazil is the main purpose of this paper which also analyzes the guiding criteria of the selection of focused clusters by the policies, as well as the scope, institutionalities and deployed instruments to carry out the support for clusters. The main typologies of clusters, whose focus is on policy objectives, constitute the analytical framework to assess how the policies to support clusters have been developed in some Brazilian states. The assessment undertaken in this work underscores, as main conclusion, a significant diversity in state policies to support clusters Key words: clusters, public policies 


\section{INTRODUÇÃO}

A partir do final dos anos 1990, começa a ganhar importância nas políticas públicas o tema das aglomerações de empresas, mais comumente denominados no Brasil arranjos produtivos locais (APLs). Sob a influência de vários estudos acadêmicos, alguns órgãos de governo, assim como governos municipais e/ou estaduais, definem ações de apoio aos APLs. Em um primeiro momento, foram ações isoladas e concebidas ad hoc, tanto pela diversidade de situações existentes nas aglomerações, como pela ausência de um eixo condutor das ações. Ademais, foram desenvolvidas em um ambiente macroeconômico muito restritivo para as atividades produtivas em geral. Neste ambiente, estas ações apresentaram resultados muito desiguais, mas foram importantes na difusão de informações e conhecimentos desta temática, ensejando um importante processo de aprendizado institucional.

Com a definição da Política Industrial, Tecnológica e de Comércio Exterior em 2003, o Governo Federal altera a situação vigente em relação ao reconhecimento da importância de ações de apoio ao setor produtivo e, no que respeita aos APLs, reconhece seu status e dá início à institucionalização da política. Com este objetivo, foi criado em 2004 um grupo de trabalho, o GTP$\mathrm{APL}^{1}$, no âmbito do Ministério do Desenvolvimento, Indústria e Comércio Exterior (MDIC), que coordena as ações de entidades públicas e privadas e governos estaduais envolvidos com a temática das aglomerações (BRASIL, 2004). O objetivo inicial da criação deste grupo foi o de articular e integrar as ações que, desde alguns anos, estavam sendo instituídas para as aglomerações por distintos órgãos de governo e entidades privadas. Outros Ministérios, como o da Ciência e Tecnologia (MCT), Integração (MI) e Minas e Energia (MME), engajaram-se nesta temática e também empreendem ações voltadas ao apoio à APLs.

Entre o final dos anos 1990 e o início dos anos 2000, a partir de caminhos próprios ou sob influência das políticas em nível federal, os estados brasileiros dão início às suas políticas de apoio à APLs. A análise de como estas políticas foram implementadas nos estados do Centro-Sul do Brasil é o objetivo principal deste artigo. São analisados os critérios norteadores da seleção dos arranjos focalizados pelas políticas, assim como o escopo, institucionalidade e instrumentos mobilizados para levar a cabo o apoio aos APLs.

Em função do curto período de tempo de implementação das políticas, assim como de dificuldades metodológicas intrínsecas aos processos de avaliação, é ainda escassa a literatura dedicada à análise da avaliação das políticas para APLs no Brasil. Ao realizar um esforço de sintetizar resultados de pesquisas recentes, este artigo pretende contribuir com o avanço do conhecimento sobre como essas políticas vêm sendo implementadas em estados da região CentroSul do país.

Para cumprir o objetivo proposto, o artigo estrutura-se em duas seções, além da Introdução e Conclusão. A seção 2 apresenta as principais tipologias para APLs, cujo foco são os objetivos de política. À luz dos elementos colocados por essas tipologias, a seção 3 analisa o processo de implementação das políticas de apoio à APLs nos estados da região Centro-Sul do Brasil, com destaque para a diversidade de situações encontradas.

\section{TIPOLOGIAS PARA APLS COM FOCO EM OBJETIVOS DE POLÍTICA: uma revisão da} literatura.

A literatura nacional tem tratado do tema da dimensão local como fator determinante da capacidade inovativa e, portanto, dos arranjos produtivos locais como uma alternativa relevante de desenvolvimento econômico. Esse reconhecimento tem contribuído para que as políticas, focando conjuntos de atores, suas articulações e seus territórios estejam também na pauta de vários trabalhos acadêmicos.

Esta seção visa então, a partir de revisão bibliográfica, apresentar objetivos de política voltada para arranjos produtivos locais presentes na visão de diversos autores brasileiros. Pretendese, assim, discutir linhas de intervenção e diretrizes estratégicas de atuação que permitam enquadrar os APLs a serem selecionados e apoiados.

Nesta direção, o trabalho de Costa (2007) propõe uma taxonomia de aglomerações produtivas a partir do objetivo da intervenção. Para esse autor, a classificação dos aglomerados permite enquadrá-los com base em problemáticas capazes de fornecerem linhas gerais de intervenção. Assim, afirma que o Estado pode

[...] selecionar os casos que serão objeto de intervenção de acordo com o programa de governo e com as diretrizes estratégicas de atuação das instituições governamentais com foco no apoio ao desenvolvimento de arranjos produtivos. A intervenção, desta forma, de modo algum deve ser voluntariosa e desprovida de parâmetros que a balizem. (COSTA, 2007, p. 238). política:

Costa (2007) sugere os seguintes objetivos de

i) aumentar o grau de cooperação e coordenação nas atividades dos agentes do aglomerado;

ii) fomentar 0 desenvolvimento das empresas e, consequentemente, do aglomerado; 
iii) fomentar o desenvolvimento local e regional;

iv) fomentar a exportação e a colocação dos produtos do aglomerado em novos mercados;

v) fomentar o desenvolvimento tecnológico;

vi) promover o treinamento técnico da mão de obra e quadro administrativo, fomentar o desenvolvimento tecnológico, e melhorar a qualidade dos produtos e dos processos produtivos;

vii) melhorar a qualidade do produto e dos processos produtivos;

viii) melhorar a qualificação da mão de obra e quadro administrativo, melhorar o processo produtivo, e aumentar a qualidade do produto;

ix) aumentar o nível de formalização das empresas;

x) aumentar o nível de formalização da mão de obra; e

xi) aumentar o índice de sobrevivência das empresas.

Nessa proposta, a formulação da taxonomia calca-se no objetivo de intervenção a partir de uma tipificação das aglomerações. Para essa tipificação, o autor considera vários aspectos, como: o grau de cooperação entre os produtores; a estrutura interna do aglomerado; as características das empresas; o papel do setor público; o principal mercado atendido; a qualidade do produto; a importância para a economia local ou regional; o grau de institucionalidade; o grau de tecnologia do produto ou processo; a identidade sociocultural; a qualificação da mão de obra; a qualificação do quadro administrativo; a presença de instituições de pesquisa; o nível de informalidade das empresas; o índice de sobrevivência das empresas, dentre outras (COSTA, 2007, p. 228-229).

Ainda com relação à tipificação dos arranjos, outros trabalhos que também discutem as dimensões principais dos APLs podem ser mencionados. Britto (2000), por exemplo, assinala que a "estrutura" interna das aglomerações envolve uma série de elementos, tais como: o padrão de especialização setorial das mesmas; o tamanho relativo de seus membros participantes; as articulações interindustriais subjacentes; os padrões de concorrência que prevalecem nos mercados respectivos e as vantagens competitivas que podem ser geradas a partir da estruturação desses arranjos (BRITTO, 2000).

Cassiolato e Szapiro (2003), por sua vez, destacam três dimensões principais para auxiliar na classificação dos arranjos: o grau de territorialidade, a forma de governança e o mercado de destino da produção do arranjo. Quanto à governança, pode se dar através de formas hierárquicas ou em forma de redes. Com relação ao destino da produção local, pode ser o mercado local/regional, regional/nacional, ou ainda nacional/internacional. $\mathrm{E}$, finalmente, quanto ao grau de territorialidade das atividades produtivas e inovativas, isto é, quanto ao enraizamento local das capacitações necessárias às atividades inovativas, essa territorialidade pode ser alta, média ou baixa.

Já Suzigan e outros (2004) descrevem quatro tipos de arranjos, que são: (1) vetor de desenvolvimentolocal; (2) núcleo de desenvolvimento setorial-regional; (3) vetor avançado; e (4) embrião de arranjo produtivo.

A partir da lógica de desenvolvimento dos APLs, em um dos extremos têm-se os "embriões de APLs", que se caracterizam por ainda serem incipientes tanto em termos da importância que apresentam para o local quanto para o setor produtivo ao qual pertencem, e em outro os "núcleos de desenvolvimento setorial-regional". Em termos de políticas de intervenção para esses dois extremos, Suzigan, Furtado e Garcia (2007) mencionam que para os embriões a política deve incluir ações com foco na função de comercialização (ex.: pesquisas de mercado) e capacidade de produção. As primeiras devem servir para ajudar as empresas a identificarem nichos de mercado que possam ser explorados por atividades promocionais coordenadas, visto que essa parece ser uma forma adequada de evitar a expansão não organizada da capacidade de produção e, assim, o aumento da produção acompanhado de redução de preço e qualidade. As ações também devem incluir medidas que ofereçam condições para a aquisição de capacidades produtivas para que as empresas tenham condições tecnológicas de atingir os mercados-alvo escolhidos.

Para os APLs denominados de "núcleos de desenvolvimento setorial-regional', ações políticas adequadas devem ser aquelas que objetivam reduzir ou eliminar a dependência de canais de venda e estimular o desenvolvimento de produtos, de marcas, de registro de patentes, design e certificações de qualidade. Ainda, são fundamentais as ações voltadas para a educação e treinamento técnico.

Como os APLs classificados como "vetores de desenvolvimento local" constituem sistemas que já superaram o estágio embrionário, as políticas deveriam ajudá-los a: desenvolver capacidades técnicas superiores (P\&D, marcas próprias, design, patentes, certificações da qualidade), e identificar mais facilmente novas oportunidades.

Já os sistemas do tipo vetores avançados são sistemas inseridos em estruturas econômicas diversificadas e integradas. Políticas para esses vetores deveriam buscar mobilizar os próprios recursos locais avançados que constituem o tecido econômico circundante e que diferenciam esses vetores dos outros tipos de sistemas locais de produção. 
De todo modo, qual seja a denominação empregada, ao examinar-se os diferentes casos estudos pela Rede Sist ao longo de vários anos, observa-se que há nitidamente APLs em estágios de estruturação distintos. Arranjos com a mesma especialização setorial, mas localizados em diferentes regiões apresentam características singulares. Isto é, ao pensar-se em políticas para arranjos deve-se levar em conta suas trajetórias evolutivas, já que tais estágios, sejam emergentes, sejam de consolidação, implicam em ações distintas e específicas.

Quando se analisa ainda a natureza do objeto e as necessidades específicas dos APLs, Scatolin (2009) observa que a literatura tem agrupado as políticas públicas em APLs em três grandes direções:

- Políticas de engajamento dos atores que envolvem desde políticas voltadas à conscientização e aproximação dos diferentes atores, até políticas de mobilização destes atores e o suporte à governança local. Procuram ainda fomentar a maior cooperação dos agentes para o sucesso dos APLs.

- O segundo conjunto de políticas públicas se refere às políticas de prestação de serviços coletivos, que visam reduzir custos e ampliar a competitividade sistêmica, como a construção de espaço coletivo para facilitar o acesso aos mercados pelos APLs, políticas para reduzir custos de compra de insumos, ou mesmo políticas para qualificar a mão de obra local.

- A terceira direção envolve políticas de P\&D que em ações conjuntas ou mesmo individuais procuram reforçar a capacidade de aprendizado e inovação do APL.

Também levando em conta a natureza do objeto, para Campos (2009), a formulação da política voltada aos arranjos produtivos locais deveria levar em conta o papel estratégico que esse objeto da política - o APL - possa ter. Assim, para esse autor,

[...] não se trata de criar ou não APLs, mas de após um diagnóstico regional, no qual está logicamente considerado a dimensão produtiva, identificar como as aglomerações ali presentes podem ser instrumentos de política para os objetivos articulados do desenvolvimento produtivo com o desenvolvimento regional do local em questão. (CAMPOS, 2009, p. 54-55).

Em outras palavras, a política de apoio aos APLs deve considerá-los instrumentos que articulem as estratégias de desenvolvimento regional e produtivo-tecnológico, assim como as priorizações e os programas específicos para cada APL devem ser orientados pela função que o APL possa ter no espaço de sua localização, como instrumento da estratégia de política definida. Consideradas essas premissas, Campos (2009) propõe um elenco de estratégias, conforme se vê abaixo.

i) APLs para estímulo a regiões deprimidas;

ii) APLs para desenvolvimento de setores absorvedores de mão de obra;

iii) APLs para desenvolvimento competitivo de setores exportadores;

iv) APLs para desenvolvimento tecnológico de setores intensivos em conhecimento;

v) APLs para estímulos a serviços geradores de renda local;

vi) APLs para complementação de cadeias produtivas regionais.

Nessa proposta, os arranjos podem ser pensados como instrumentos para atingir uma série de objetivos. Logo, para cada objetivo estratégico poder-se-ia pensar num conjunto de ações dentro dos eixos que hoje já balizam a atuação dos órgãos do GTP - APL, que são: acesso a mercados; capacidade produtiva; financiamento e investimento; formação e capacitação; governança e cooperação; e inovação e tecnologia.

Assim, no caso de APLs voltados para - desenvolvimento competitivo de setores exportadores, por exemplo, poder-se-ia desenvolver algumas ações específicas dentro de cada eixo. No eixo inovação e tecnologia, poder-se-ia focar na infraestrutura de serviços de certificação e normatização, no desenvolvimento de marca própria e em design; no eixo governança e cooperação, fomentar a criação de consórcios de exportação; no eixo financiamento e investimento, em linhas de crédito para exportação; e no eixo formação e capacitação, promover o fortalecimento de capacitações inovadoras.

Embora interessante, tal proposta pode trazer dificuldades para o enquadramento dos arranjos já que um mesmo APL poderia ser classificado, por exemplo, como instrumento para o desenvolvimento competitivo de setores exportadores e também como instrumento para o desenvolvimento de setores intensivos em mão de obra, como é a realidade de muitos dos arranjos calcados em segmentos industriais tradicionais. Tal questão poderia ser resolvida via tomada de decisão da instituição apoiadora, isto é, ainda que o mesmo APL possa ser objeto de mais de uma estratégia, haveria uma opção por um objetivo de intervenção quando da seleção deste arranjo para apoio. O que não significa que em um momento subsequente esse mesmo APL possa ser alvo de outra estratégia, não excludente.

Cassiolato, Lastres e Szapiro (2000) quando analisam a questão de políticas para aglomerações produtivas, também apresentam os objetivos que as iniciativas que visam a transformação de aglomerações produtivas em sistemas locais de produção devem ter. Esses são: (1) revolucionar e estimular o ambiente 
local, por meio de ações voltadas, por exemplo, para a educação, aprendizado e capacitação, para a difusão de informações críticas, articulação com universidades e centros de pesquisa; (2) superar gargalos e alcançar economias de escala coletivas; (3) obter economias externas; e (4) fortalecer a sinergia entre os diversos atores do aglomerado.

Enfim, para encerrar essa seção, cabe ressaltar especialmente dois pontos. O primeiro é que a partir do que foi apresentado verifica-se que há diversas perspectivas de enxergar a política, o que implica um elenco diverso de alternativas e possibilidades para classificar os arranjos a partir de objetivos de intervenção. Não há assim, sem dúvida, uma fórmula única.

O segundo ponto é que tal variedade é resultado de uma agenda intelectual particular e não idêntica que parte de "óculos" diferentes. Logo, deve ser vista com cautela já que pode ser reducionista de uma realidade complexa. Por outro lado, pode ser de tal forma ampla, que tudo cabe. Nesse sentido, nas propostas apresentadas podese, por exemplo, identificar objetivos como aumentar o nível de formalização das empresas e aumentar o índice de sobrevivência das empresas que de tão genéricos aplicam-se a tudo, e pouco se vinculam aos aspectos-chave do conceito de sistema e arranjos produtivos e inovadores locais; o que reduz a possibilidade de aproveitar as vantagens desse enfoque.

Deve-se então ter atenção às tipologias genéricas, pois as realidades estaduais e locais possuem especificidades que devem ser levadas em conta. A seguir, busca-se trazer para o debate a experiência de implementação de políticas de apoio a arranjos a partir da análise dos casos da região sul.

\section{EXPERIÊNCIAS ESTADUAIS DE APOIO AAPLS NA REGIÃO CENTRO-SUL DO BRASIL}

A forma como a política para APLs tem sido implementada nos estados brasileiros é bastante distinta, do ponto de vista (i) do período em que as ações começaram a ser implementadas e como tiveram continuidade (ou não) ao longo do tempo; (ii) dos procedimentos e conceitos que orientaram a seleção dos arranjos a serem apoiados; e (iii) dos instrumentos de política mobilizados para a efetivação da política.

Com base em um amplo projeto de pesquisa sobre este tema ${ }^{2}$, esta seção dedica-se à análise dos itens elencados acima, de modo a se ter uma avaliação de como se desenvolve a política para APLs no Brasil à luz das tipologias analisadas na seção anterior. A ressalva, em relação aos estados analisados, é a de que não se pretende abordar exaustivamente os temas acima apontados em cada um dos estados da região Centro-Sul. Conforme já indicado, estudos específicos sobre as políticas em cada um destes estados já foram realizados.
A intenção aqui é de analisar estes estudos à luz das tipologias anteriormente apresentadas, de modo a se ter uma avaliação de como vêm sendo implementadas as políticas para APLs no Brasil.

\subsection{Procedimentos e conceitos orientadores da seleção dos arranjos apoiados}

As diferenças apontadas em relação ao momento da implementação das políticas para APLs também aparecem quando se consideram o conceito de APL que orientou a seleção dos arranjos a serem apoiados em cada estado.

Observa-se, a partir da leitura dos dados da Tabela 1, que há grandes diferenças em termos de número de arranjos apoiados em cada estado. Os números são muito díspares e, ademais, verificase que em estados com estruturas produtivas mais diversificadas e complexas, como São Paulo, Minas Gerais, Rio Grande do Sul e Paraná, o número de APLs apoiados é relativamente menor frente aos demais estados.

Conforme as análises estaduais apontam, diferentes conceitos de APL orientaram a seleção dos arranjos, embora nem sempre esteja claro nos documentos oficiais quais os critérios orientadores da seleção. Há casos, como o de Minas Gerais e o do Paraná, que mapeamentos a partir de rigorosos critérios estatísticos foram elaborados e influenciaram, em maior (caso do Paraná) ou em menor grau (em Minas Gerais), a escolha dos APLs atualmente apoiados. No caso destes dois estados, são excluídos das políticas os arranjos produtivos que se formam a partir de redes de fornecimento em torno a uma grande empresa. Mesmo considerandose este ponto em comum entre os dois estados, verifica-se que no caso do Paraná a opção explícita foi a de considerar o conceito de Sistemas Locais de Produção que se traduz em "vetor de desenvolvimento local", da tipologia de Suzigan e outros (2004). Com isso, são selecionados apenas os arranjos mais bem estruturados e que apresentam vínculos de cooperação e aprendizagem (Scatolin et al, 2010).

Tabela 1 - Arranjos produtivos locais apoiados por estado

\begin{tabular}{l|l|l}
\hline \multirow{2}{*}{ APLs/Estado } & \multicolumn{2}{|c}{ No. de APLs } \\
\cline { 2 - 3 } & Apoiados & $\begin{array}{c}\text { \% do total de } \\
\text { apoiados }\end{array}$ \\
\hline Rio Grande do Sul & 33 & $7,75 \%$ \\
\hline Santa Catarina & 69 & $16,20 \%$ \\
\hline Paraná & 22 & $5,16 \%$ \\
\hline São Paulo & 27 & $6,34 \%$ \\
\hline Minas Gerais & 34 & $7,98 \%$ \\
\hline Rio de Janeiro & 69 & $16,20 \%$ \\
\hline Espírito Santo & 18 & $4,23 \%$ \\
\hline Goiás & 59 & $13,85 \%$ \\
\hline Mato Grosso do Sul & 95 & $22,30 \%$ \\
\hline Total & 426 & $100,00 \%$ \\
\hline Fonte: Campos outros $(2010, p .44)$ &
\end{tabular}

Fonte: Campos e outros (2010, p. 44). 
Já no estado de Minas Gerais, a seleção dos APLs apoiados parece obedecer a critérios mais difusos, podendo identificar-se arranjos com características muito distintas em termos de estruturação e grau de desenvolvimento. No que respeita às tipologias discutidas na seção anterior, encontram-se no estado de Minas Gerais os quatro tipos de arranjos identificados em Suzigan e outros (2004), ademais de identificar-se todos os objetivos de políticas apresentados por Campos (2009), a saber, estímulo a regiões deprimidas, a setores absorvedores de mão de obra, a setores exportadores, a setores intensivos em conhecimento, serviços geradores de renda local e à complementação de cadeias produtivas regionais (BOTELHO et al, 2010). Conforme já apontado, em alguns arranjos estes objetivos superpõem-se.

À semelhança de Minas Gerais, no caso do Rio Grande do Sul, também objetivos muito distintos estão por trás da seleção dos APLs atualmente apoiados no estado. Segundo Tatsch, Ruffoni e Batisti (2009), na primeira fase da política de apoio a APLs (1998-2002), houve uma maior reflexão para seleção dos arranjos a serem objeto da política pública, quando o processo de identificação baseouse principalmente no conhecimento empírico de especialistas envolvidos com a política sobre a estrutura produtiva das regiões gaúchas. Assim, ao invés de metodologias calcadas em quocientes locacionais, os conhecimentos, tácito e codificado, do histórico das regiões gaúchas foram o principal elemento para orientar a identificação dos arranjos. Já nas fases subsequentes (2003-2006 e 20072010), o processo de seleção é balizado por demandas sociais e pressões políticas e menos por estudos sistematizados sobre a situação socioeconômica gaúcha.

Os casos analisados mostram que diferentes critérios orientaram a seleção de APLs a serem apoiados nos estados brasileiros. A literatura internacional destaca três formas principais para a seleção de arranjos, a saber: os mapeamentos realizados com critérios estatísticos e econométricos, a identificação por governos locais e a autoidentificação, especialmente presentes em chamadas públicas para financiamento ou outras formas de apoio (ORGANIZATION FOR ECONOMIC COOPERATION AND DEVELOPMENT, 2007).

À exceção do estado do Paraná, onde a identificação ocorreu com base, sobretudo, em um mapeamento elaborado com critérios estatísticos, nos demais estados do centro-sul do país mesclamse estes três critérios, às vezes em momentos distintos do tempo, conforme ocorrido no estado do Rio Grande do Sul.

Sobre a terceira forma indicada acima, a da autoidentificação, verifica-se a sua ocorrência no Brasil quando da inclusão da temática de APLs nas políticas públicas estaduais e federais na primeira metade dos anos 2000. Como um conjunto de instrumentos de política, passou a orientar-se para o apoio às aglomerações de empresas, diversas estruturas econômicas e regiões apresentaram-se como APLs, levando à avaliação de que estavam sendo "criados" de modo artificial. Se, de um lado, isso pode ter ocorrido em alguns casos, de outro lado, a possibilidade de inserir-se nas políticas públicas levou os agentes de várias regiões a empreenderem planos de desenvolvimento conjunto e a ganhar visibilidade política, o que contribuiu para o ressurgimento de políticas de corte regional no Brasil, que vinham sendo relegadas a segundo plano pelo "modelo liberalizante" dos anos 1990.

A análise da diversidade nos critérios de seleção de APLs para apoio nos estados brasileiros pode ser complementada com as informações da Tabela 2.

A análise destes dados e de documentos específicos das pesquisas estaduais indica que a seleção das aglomerações apoiadas por políticas é condicionada pelo conceito que orienta a política, tal como discutido anteriormente, e pelas estruturas produtivas estaduais.

No caso dos estados mais industrializados (São Paulo, Minas Gerais, Paraná, Rio Grande do Sul e Rio de Janeiro), a ênfase da política recai nos arranjos industriais. Considerando-se que estes estados apresentam um número pequeno de arranjos apoiados, frente a outros estados e à sua estrutura mais diversificada e complexa, pode-se inferir que a política para arranjos produtivos poderia abarcar um conjunto muito maior de estruturas do que o atualmente realizado. Ademais, deve-se ter em conta que estes estados, além de contar com um grau mais avançado de industrialização, contam também com um setor agroindustrial e de serviços igualmente diversificado e complexo. Estas considerações levam à conclusão de que a política para arranjos nestes estados não se integra, de fato, às suas políticas de desenvolvimento produtivo ${ }^{3}$. A "visão" por trás da escolha dos arranjos tende a privilegiar o setor industrial e, dentro dele, ora arranjos mais estruturados e com maior visibilidade política, ora arranjos que se apresentam como a principal opção para alavancar o crescimento de regiões mais atrasadas e com baixo nível de renda.

A importância da estrutura produtiva na seleção dos arranjos fica clara quando se analisam os estados menos industrializados. Nestes, em especial em Mato Grosso, Santa Catarina e Goiás, há um conjunto significativo de APLs de base agroindustrial e, no Espírito Santo, os APLs no setor de serviços apresentam-se com grande relevância (um terço do total de arranjos apoiados) ${ }^{4}$.

A principal conclusão a ser extraída destas informações é que a política para APLs seguiu caminhos muito distintos nos estados brasileiros. Não se encontra, dentre os vários estados analisados, nenhuma uniformidade quanto aos critérios para a seleção de arranjos e, tampouco, "visões"/conceitos mais homogêneos do que sejam estas estruturas. 
Tabela 2 - Distribuição dos arranjos produtivos locais por estado e por atividade econômica

\begin{tabular}{|c|c|c|c|c|c|c|c|c|c|}
\hline \multirow[b]{2}{*}{$\begin{array}{c}\text { Atividade } \\
\text { econômica/estado }\end{array}$} & \multicolumn{2}{|c|}{ Agroindústria } & \multicolumn{2}{|c|}{ Indústria (1) } & \multicolumn{2}{|r|}{ Serviços } & \multicolumn{2}{|r|}{ Comércio } & \multirow[b]{2}{*}{ Total } \\
\hline & No. & $\begin{array}{c}\% \text { do total do } \\
\text { estado }\end{array}$ & No. & $\begin{array}{c}\% \text { do total do } \\
\text { estado }\end{array}$ & No. & $\begin{array}{l}\% \text { do total } \\
\text { do estado }\end{array}$ & No. & $\begin{array}{c}\% \text { do total do } \\
\text { estado }\end{array}$ & \\
\hline Rio Grande do Sul & 8 & $24,24 \%$ & 22 & $66,67 \%$ & 3 & 9,09 & 0 & $0,00 \%$ & 33 \\
\hline Santa Catarina & 24 & $34,78 \%$ & 28 & $40,58 \%$ & 14 & 20,29 & 3 & $4,35 \%$ & 69 \\
\hline Paraná & 0 & $0,00 \%$ & 17 & $77,27 \%$ & 5 & 22,73 & 0 & $0,00 \%$ & 22 \\
\hline São Paulo & 1 & $3,70 \%$ & 26 & $96,30 \%$ & 0 & 0,00 & 0 & $0,00 \%$ & 27 \\
\hline Minas Gerais & 4 & $11,76 \%$ & 28 & $82,35 \%$ & 2 & 5,88 & 0 & $0,00 \%$ & 34 \\
\hline Rio de Janeiro & 15 & $21,74 \%$ & 40 & $57,97 \%$ & 13 & 18,84 & 1 & $1,45 \%$ & 69 \\
\hline Espírito Santo & 1 & $5,56 \%$ & 9 & $50,00 \%$ & 2 & 11,11 & 6 & $33,33 \%$ & 18 \\
\hline Goiás & 19 & $32,20 \%$ & 27 & $45,76 \%$ & 12 & 20,34 & 1 & $1,69 \%$ & 59 \\
\hline Mato Grosso do Sul & 68 & $71,58 \%$ & 18 & $18,95 \%$ & 4 & 4,21 & 5 & $5,26 \%$ & 95 \\
\hline Total & 140 & $32,86 \%$ & 215 & $50,47 \%$ & 55 & 12,91 & 16 & $3,76 \%$ & 426 \\
\hline
\end{tabular}

(1) Neste conjunto de APLs estão agrupados os arranjos relacionados às atividades da indústria de transformação e da indústria da extração mineral.

A principal conclusão a ser extraída destas informações é que a política para APLs seguiu caminhos muito distintos nos estados brasileiros. Não se encontra, dentre os vários estados analisados, nenhuma uniformidade quanto aos critérios para a seleção de arranjos e, tampouco, "visões"/conceitos mais homogêneos do que sejam estas estruturas. De um lado, a não uniformidade/homogeneidade tem o papel benéfico de trazer à tona a diversidade de estruturas que podem ser consideradas sob esse referencial teórico/conceitual. Conforme estudo recente elaborado pela OECD (2007) há uma significativa diversidade na aplicação das denominadas clusters policies. O documento indica que a forma como cada país aplica esta política relaciona-se estreitamente com os objetivos mais gerais da política voltada ao setor produtivo e com a "visão" que se adota para os clusters ${ }^{5}$.

The challenge for policy makers at the national level is thus to design programmes that accommodate the broad range of clusters types or that focus on those clusters that can help achieve specified objective. The concept of clusters may be used in advanced and lagging regions, for SME-based or multi-firm size systems, to serve new and mature industries, to target existing concentrations or to generate new ones. The common assumption is that some advantages can be derived in each situation from the process of interaction and collaboration are present, albeit in different degrees in each type of place. (ORGANIZATION FOR ECONOMIC COOPERATION AND DEVELOPMENT, 2007, p. 37).

Poroutrolado, pode-se destacar, como aspecto negativo da não uniformidade/homogeneidade com que as políticas para APLs têm sido implementadas, o fato de na maior parte dos estados a seleção não abarcar todas as estruturas que poderiam ser consideradas, apresentando-se como restritiva:

(i) do ponto de vista setorial-nos estados que tendem a privilegiar os setores industriais
(São Paulo, Minas Gerais, Paraná, Rio Grande do Sul e Rio de Janeiro);

(ii) do ponto de vista regional-especialmente nos estados que privilegiam os arranjos maiores e melhor estruturados, tendo a política para APLs o viés de reforçar desigualdades regionais (Paraná);

(iii) do ponto de vista do tipo de arranjo contemplado - característico de estados que excluem da política arranjos formados por redes de fornecimento em torno de uma grande empresa, por exemplo (Paraná e Minas Gerais).

\subsection{Escopo, institucionalidade e instrumentos da política de apoio a APLs}

A significativa diversidade verificada nos métodos de seleção de APLs apoiados nos estados do Centro-Sul do país também se apresenta quando da análise do escopo, institucionalidade e dos principais instrumentos mobilizados para levar a cabo as políticas estaduais de apoio a arranjos produtivos.

Em termos de escopo e institucionalidade, pode-se dizer que duas situações principais se apresentam: (i) estados que articularam ou que tentam articular as políticas para APLs às suas políticas mais gerais de desenvolvimento produtivo; (ii) estados cuja política parece, em organismos específicos, sem um eixo condutor dado pela política governamental.

No primeiro caso, destaca-se o estado do Rio Grande do Sul como estado pioneiro na implementação de ações voltadas aos APLs por parte da Secretaria do Desenvolvimento e dos Assuntos Internacionais (SEDAl) no período de 1999 a 2002, antecedendo, portanto, as políticas de cunho federal ${ }^{6}$. Conforme Tatsch, Ruffoni e Batisti (2009), um conjunto de ações começou a ser empreendido nestes anos, com destaque para a articulação com a política estadual de inovação, que culminou com a criação, em 2002, dos Centros Gestores de Inovação, que buscavam difundir tecnologias dentro do ambiente produtivo local. 
A despeito do caráter pioneiro, a política gaúcha de apoio à APLs perde importância nos anos subsequentes, o que aponta para um problema que se reproduz em vários estados, a saber, o das mudanças institucionais que ocorrem quando da alternância de partidos políticos no poder. Este aspecto das políticas para APLs remete à fragilidade do quadro institucional de apoio ao desenvolvimento produtivo no Brasil?.

Também no caso do estado do Paraná, a política estadual de apoio à APLs sofre um recuo. Scatolin e outros (2010) mostram que a Rede APLs, instituição formada pela Secretaria de Planejamento, pelo SEBRAE-PR e pela Federação das Indústrias do Paraná (FIEP), com o propósito de coordenar a política estadual de APLs, sofreu um processo de esvaziamento no período posterior ao das articulações levadas a cabo para a sua formação e consolidação.

A descontinuidade na aplicação da política para APLs nos estados brasileiros também ocorreu, embora com características distintas das apresentadas no Rio Grande dos Sul, no estado de Goiás. O motivo determinante da descontinuidade foi uma mudança administrativa que, ao ser discutida e posteriormente implementada, desarticulou organismos e pessoal que já tinham adquirido expertise na política de apoio à APLs (CASTRO; ESTEVAM, 2010).

Portanto, mesmo em estados em que a política de apoio à APLs esteve mais articulada com a política de desenvolvimento produtivo, verificam-se processos de descontinuidade em sua aplicação. $O$ cumprimento dos objetivos inicialmente delineados pela política torna-se, assim, de difícil consecução e, no mais das vezes, o caminho seguido é o do esvaziamento da política, com concentração dos instrumentos de apoio em poucos arranjos e ênfase em ações mais convencionais, como políticas de corte setorial.

Políticas descontinuadas e ênfase das ações em estruturas já consolidadas impedem que se alcancem os objetivos primordiais de uma política de apoio à APLs, resumida na proposta de Cassiolato, Lastres e Szapiro (2000). Estas devem mirar a mudança das estruturas locais em direção à ampliação dos mecanismos de aprendizado e capacitação, à superação de gargalos e alcance de economias de escala coletivas e à obtenção/ fortalecimento de economias externas e sinergia entre os diversos atores do aglomerado, ações cujo prazo de maturação tende a ser longo.

Outra situação verificada em alguns estados brasileiros é a da política de apoio à APLs não se articular com as políticas estaduais de desenvolvimento produtivo, sendo levada a cabo por instituições de apoio, como SEBRAE, por exemplo.

Esta situação pode ser verificada no estado de Santa Catarina, em que o conjunto das ações se restringe a poucos órgãos que as executam e têm autonomia em relação ao governo do estado na sua formulação. "Isso faz com que a política para APLs seja na pratica a utilização desse instrumento para a execução das ações fins dos órgãos que as aplicam e não uma política de estado" (CAMPOS, 2009, p.49).

A autonomia de determinadas instituições para desenvolver ações que têm como foco o desenvolvimento regional pode ser exemplificada com a atuação do Banco do Brasil no estado de Mato Grosso do Sul. A denominada estratégia Desenvolvimento Regional Sustentável (DRS) é a responsável por identificar um grande número de municípios e regiões deste estado, cujas características socioeconômicas permitem a aplicação desta estratégia de ação do Banco .

Assim, à semelhança do que ocorre em Santa Catarina, também em Mato Grosso do Sul, as políticas de apoio à APLs são empreendidas por instituições de apoio, em especial o BB e o SEBRAE, que se orientam pelos seus objetivos institucionais, do que decorre uma desarticulação com a política estadual de apoio à APLs e com a política de desenvolvimento produtivo (LE BOURLEGAT; OLIVEIRA, 2010).

Ainda neste grupo de estados pode-se citar a experiência recente de apoio à APLs do estado do Rio de Janeiro que, ao concentrar os instrumentos de apoio em grandes projetos de investimento, trata a política para APLs como "compensatória", ou seja, voltada aos setores econômicos e regiões não alcançados pelos grandes projetos (BRITTO; VARGAS; CARVALHO, 2010).

Em suma, seja nos casos em que a política de apoio à APLs se articulou, em algum momento, à política de desenvolvimento produtivo, seja naqueles em que este caráter não foi almejado, em nenhum dos estados analisados neste trabalho evidencia-se a construção de uma institucionalidade condizente com os objetivos que se delineiam quando da definição das ações. Todos os estudos estaduais analisados apontam deficiências na institucionalidade que se forjou nos estados para a implementação da política de apoio à APLs, mesmo quando a política seguiu uma lógica própria, não sendo mero reflexo das políticas implementadas no âmbito federal após a instalação do GTP-APL.

Embora sejam distintos os aspectos elencados em cada um dos estados para substanciar as deficiências verificadas, há um ponto comum entre todos eles no que tange aos instrumentos acionados para levar adiante a política de apoio à APLs, qual seja, a inadequação das fontes de financiamento e os parcos recursos mobilizados no fomento aos arranjos selecionados como foco da política.

A inadequação das fontes de financiamento refere-se, sobretudo, à ausência de mecanismos que considerem o arranjo na sua unidade, ou seja, que abarque o coletivo de empresas e suas interações. A excessiva rigidez que caracteriza as operações do sistema bancário nacional torna os bancos avessos 
ao financiamento de empresas de pequeno porte e à implementação de instrumentos financeiros para coletivos de empresas.

Em vista desta rigidez, a política para APLs nos estados dispõe, principalmente, de recursos orçamentários e de recursos oriundos de convênios específicos que se estabelecem com organismos de apoio (SEBRAE, SENAI, e outros).

Em termos de recursos de maior monta direcionados ao apoio à APLs, destaca-se o convênio que vários estados empreenderam com o Banco Interamericano de Desenvolvimento (BID) para obter recursos de financiamento mais adequados ao apoio a coletivos de empresas. A partir de duas experiências iniciais ocorridas nos estados do Pará e Bahia, também os estados de São Paulo e Minas Gerais empreenderam acordos financeiros junto ao BID para alavancar recursos mais vultosos para o apoio à APLs.

O que se coloca como restrição a este tipo de apoio financeiro relaciona-se com o ocorrido com os estados que já firmaram convênio semelhante com esta instituição. São problemas, dentre outros, decorrentes da seleção dos arranjos a serem apoiados, onde somente os mais estruturados cumprem os requisitos para a participação; da exclusão de empresas menores, incapazes de oferecer as contrapartidas necessárias e de adequar suas estruturas de modo a viabilizar a participação no programa; da morosidade no encaminhamento das ações e liberação dos recursos; das opções estratégicas em termos de quais são os principais investimentos necessários ${ }^{9}$.

As análises para os estados do Pará e Bahia destacam como aspecto principal deste tipo de programa a sua descontextualização, decorrente do uso de critérios e metodologias que se supõe adequados a distintos contextos e que, nos processos de implementação, acabam por desarticular o tecido produtivo local e priorizar os agentes mais bem estruturados.

A opção por utilizar recursos oriundos do BID para a implementação da política de APLs reflete, em verdade, a escassez de fontes de financiamento na economia brasileira, fruto de um sistema financeiro que opera com pouca diversidade em termos de instrumentos de financiamento.

\section{CONCLUSÃO}

A análise das políticas estaduais de apoio à APLs nos estados da região Centro-Sul do Brasil revela uma grande diversidade de situações em relação ao momento de implementação, aos critérios que orientaram a seleção dos arranjos apoiados, ao escopo e institucionalidade forjados para o desenvolvimento das ações e, por fim, aos instrumentos de política acionados.

A partir dos casos dos estados analisados neste trabalho, verificou-se que os critérios adotados para o mapeamento, seleção e priorização dos APLs influenciam o número e o tipo de arranjos selecionados para apoio. Os casos analisados mostram que a falta de uma definição clara de estratégias que orientem as ações acaba fragilizando e restringindo a oportunidade de se valer do objeto APL para estimular o desenvolvimento econômico e social de forma ampla, abarcando os mais diferentes segmentos e os territórios com os mais diversos níveis de desenvolvimento.

$\mathrm{Na}$ maior parte das vezes, os critérios de seleção empregados estão relacionados ao impacto (em termos do PIB, das exportações, do emprego) e à relevância socioeconômica da atividade-chave do APL; à constituição e ao estágio de desenvolvimento do APL (considerando a presença de agentes, a governança local, os vínculos/interações entre as empresas e demais atores); e à capacidade de resposta da aglomeração ou potencialidade de desenvolvimento. Em outras palavras, dados os critérios atuais, os APLs com uma institucionalidade melhor organizada, envolvendo um número significativo de estabelecimentos, e que já contribuem de modo importante para a economia regional são aqueles com mais chance de serem apoiados. Portanto, há uma tendência a apoiar aqueles arranjos mais estruturados e dinâmicos.

O mapeamento, a seleção e a priorização dos APLs apoiados são esforços que fazem sentido, se inseridos numa estratégia maior de desenvolvimento de um estado, região ou país. Portanto, a aderência à estratégia de governo deve ser levada em conta. Em outras palavras, é necessário identificar os APLs a serem apoiados, estudar suas características e diagnosticar seus gargalos, para então atuar sobre suas realidades; contudo, tal atuação precisa ser pensada com base em uma estratégia maior de intervenção do Estado voltada para o desenvolvimento em sentido amplo.

Para se avançar na construção dessas estratégias, os elementos-chave do próprio conceito de sistemas e arranjos produtivos e inovativos locais devem ser postos em destaque. A aderência ao conceito é importante, pois só assim os objetivos serão orientados prioritariamente para a criaçãodifusão de conhecimento, para o estímulo a múltiplas formas de aprendizado e para a construção de competências que potencializem e ampliem a competitividade dos espaços locais (CASSIOLATO; LASTRES; SZPIRO, 2000).

Nesta direção, vale destacar que o termo sistema/arranjo resgata a dimensão local, enfatizando a questão do aprendizado, da inovação e do território. Logo, dimensões como enraizamento, adensamento e aprendizado devem orientar a construção da política de apoio à APLs. São esses atributos que se deve buscar estimular e, portanto, os objetivos da intervenção devem estar alinhados a eles. 
Ao reconhecer-se o papel central das inovações e dos processos de aprendizado que estão em sua origem, bem como sua dimensão territorial, a política deve ser pensada para todo tipo de arranjo, seja mais ou menos estruturado, cujo protagonismo seja do segmento manufatureiro, de serviços, de comércio ou vinculado a atividades culturais. De todo modo, o que não deve ser esquecido é que a política não pode ser padronizada, devendo levar em conta as especificidades do local. Uma política descontextualizada tem grande chance de ser ineficiente, como mostram os estudos que analisam as consequências da adoção dos financiamentos do BID aos APLs de alguns estados brasileiros. Portanto, a diversidade dos diferentes territórios deve ser reconhecida.

Conforme já destacado neste trabalho, as ações estaduais com vistas à implementação de políticas de apoio à APLs são, no mais das vezes, muito recentes. Os organismos de apoio ainda não dispõem de estudos mais sistemáticos que empreendam avaliações das ações efetivamente implementadas. Com isso, a literatura voltada à avaliação de políticas em APLs ainda é muito escassa. Embora de maneira limitada, o objetivo do presente trabalho foi o de contribuir para esta discussão.

\section{REFERÊNCIAS}

BOTELHO, M. R. A. et al. Políticas para arranjos produtivos locais no estado de Minas Gerais: institucionalidade, mapeamentos e focos. In: CAMPOS, Renato R. et al (Orgs.). Políticas Estaduais para arranjos produtivos locais no Sul, Sudeste e Centro-Oeste do Brasil. Rio de Janeiro: E-papers, 2010. p. 183-214

BRASIL. Ministério do Desenvolvimento, Indústria e Comércio Exterior. Termo de referência para política nacional de apoio ao desenvolvimento de arranjos produtivos Locais. Brasília, DF: MDIC/ GTP-APL, 2004.

BRITTO, J. Caracteristicas estruturais dos cluster industriais na economia brasileira. In: Projeto de pesquisa arranjos e sistemas produtivos locais e as novas politicas de desenvolvimento industrial e tecnológico: versão preliminar. Rio de Janeiro: IE/UFRJ 2000. (Nova Técnica, n. 29).

;VARGAS,M.A.;CARVALHO, G.N.P.Políticas para arranjos produtivos locais no estado do Rio de Janeiro: aspectos conceituais, institucionalidade e perspectivas de desenvolvimento. In:

CAMPOS, R. R. (Coord.). Relatório Final: síntese dos resultados, conclusões e recomendações Santa Catarina. Rio de Janeiro: BNDES, 2009. Disponível em: <http://www.politicaapls.redesist. ie.ufrj.br/>. Acesso em: 1 jun. 2012. et al (Orgs.). Políticas Estaduais para arranjos produtivos locais no Sul, Sudeste e Centro-Oeste do Brasil. Rio de Janeiro: E-papers, 2010. p. 215-55.

; et al. Políticas estaduais para arranjos produtivos locais no Sul, Sudeste e CentroOeste do Brasil. Rio de Janeiro: E-papers, p. 183214, 2010.

BITENCOURT, P.F.; SILVA, V. A. Santa Catarina: as possibilidades de políticas para arranjos produtivos locais. CAMPOS, R.; STALLIVIERI, F.; VARGAS, M. A., MATOS, M. (Orgs.). Políticas estaduais para arranjos produtivos locais no Sul, Sudeste e Centro-Oeste do Brasil. Rio de Janeiro, 2010. p. $89-112$.

CASSIOLATO, J. E.; LASTRES, H. M. M.; SZAPIRO; M. Arranjos e sistemas produtivos locais e proposições de políticas de desenvolvimento industrial e tecnológico. Rio de Janeiro: IE/UFRJ, 2000. (Nota técnica 27).

STALLIVIERI, F. Políticas estaduais e mobilização de atores em arranjos produtivos locais. CASSIOLATO, J. E.; LASTRES, H.; STALLIVIERI, F. (Orgs.). Arranjos produtivos locais: uma alternativa para o desenvolvimento. Rio de Janeiro: E-papers, 2008.

SZAPIRO; M. Uma caracterização de arranjos produtivos locais de micro e pequenas empresas. In: LASTRES, H. M. M.; CASSIOLATO, J. E.; MACIEL, M. L. (Orgs.) Pequena Empresa: cooperação e desenvolvimento local. Rio de Janeiro: Relume Dumará: UFRJ, Instituto de Economia, 2003. p. $35-50$.

CASTRO, S. D.; ESTEVAM L. A. Análise crítica do mapeamento e políticas para arranjos produtivos locais no estado de Goiás. CAMPOS, R. et al (Orgs.). Políticas estaduais para arranjos produtivos locais no Sul, Sudeste e Centro-Oeste do Brasil. Rio de Janeiro: E-papers, 2010. p. 335-370.

E. J. M. Políticas públicas e o desenvolvimento de arranjos produtivos locais em regiões periféricas. 2007. Tese (Doutorado em Economia) - Universidade Estadual de Campinas, Campinas, 2007.

F. A.; ANDRADE, W. D. C. Mudança institucional e path dependence: as políticas para arranjos produtivos locais no Pará. In: CASSIOLATO, J. E.; LASTRES, H.; STALLIVIERI, F. (Orgs.). Arranjos produtivos locais: uma alternativa para o desenvolvimento. Rio de Janeiro: E-papers, 2008. 
FERREIRA, JR., H. M., et al Política para a promoção de arranjos produtivos e inovativos locais na Bahia. In: CASSIOLATO, J. E.; LASTRES, H.; STALLIVIERI, F. (Orgs.). Arranjos produtivos locais: uma alternativa para o desenvolvimento. Rio de Janeiro: E-papers, 2008.

LE BOURLEGAT, C. A.; OLIVEIRA, M. A. C. Políticas públicas e mapeamento de APLs em Mato Grosso do Sul. CAMPOS, R.; STALLIVIERI, F.; VARGAS, M. A., MATOS, M. (Orgs.). Políticas estaduais para arranjos produtivos locais no Sul, Sudeste e Centro-Oeste do Brasil. Rio de Janeiro: E-papers, 2010. p. 291-334.

ORGANIZATION FOR ECONOMIC COOPERATION AND DEVELOPMENT. Competitive Regional Clusters: national policy approaches. Paris, may. 2007.

SCATOLIN, F. D. (Coord.). Relatório Final: síntese dos resultados, conclusões e recomendações Paraná. Rio de Janeiro: BNDES, 2009. Disponível em:<http://www.politicaapls.redesist.ie.ufrj. br/>. Acesso em: 1 jun. 2012.

et al. Análise do mapeamento e das políticas para arranjos produtivos locais no Estado do Paraná. CAMPOS, R.; STALLIVIERI, F.; VARGAS, M. A., MATOS, M. (Orgs.). Políticas estaduais para arranjos produtivos locais no Sul, Sudeste e Centro-Oeste do Brasil. Rio de Janeiro: E-papers, 2010. p. 113-138.

SUZIGAN, W. et al. Sistemas locais de produção: mapeamento, tipologia e sugestões de políticas. Revista de Economia Política, São Paulo, v. 24, n. 4, p. 543-562, 2004.

; FURTADO, J. Instituições e Políticas Industriais e Tecnológicas: Reflexões a partir da Experiência Brasileira. Estudos Econômicos, São Paulo, v. 40, n. 1, p. 7- 41, 2010.

; FURTADO, J.; GARCIA, R. C. Designing policies for local production systems: a methodology based on evidence from Brazil. Revista Economia, Brasília, DF, v. 8, p. 161-186, 2007.

TATSCH, A. L.; RUFFONI, J.; BATISTI, V. Trajetória, análise e diretrizes para a política de apoio a arranjos produtivos locias no Rio Grande do Sul. CAMPOS, $\mathrm{R}$. et al (Orgs.). Políticas estaduais para arranjos produtivos locais no Sul, Sudeste e CentroOeste do Brasil. Rio de Janeiro: E-papers, 2010. p. 55-87.

VILLASCHI, A.; FELIPE, E. S. Políticas estaduais para arranjos produtivos locais no Espírito Santo: evolução e perspectivas. CAMPOS, R. et al (Orgs.). Políticas estaduais para arranjos produtivos locais no Sul, Sudeste e Centro-Oeste do Brasil. Rio de Janeiro: E-papers, 2010. p. 257-290.
Notas

Grupo de Trabalho Permanente de Arranjos Produtivos Locais, criado pela Portaria Interministerial no. 200, de 3 de agosto de 2004 e, desde esta data, tem sido reeditada (BRASIL, 2004).

2 Análise do Mapeamento e das Políticas para Arranjos Produtivos Locais no Sul, Sudeste e Centro-Oeste do Brasil, cuja síntese está publicada em Campos, Bitencourt e Silva (2010).

3 Este argumento será retomado na sub-seção seguinte.

4 Estão inseridos na política arranjos de distintas atividades como turismo, logística e software (VILLASCHI; FELIPE, 2010).

5 O documento da OECD (2007) destaca os conceitos mais comumente utilizados: distritos industriais, sistemas de produção, sistemas regionais de inovações e redes de firmas. No caso brasileiro, a expressão mais difundida é a de arranjos produtivos locais (APLs). Ressalte-se que o conteúdo conceitual e normativo destas expressões nem sempre são equivalentes.

6 Em nível federal, a primeira ação mais articulada de apoio à APLs foi instituída em 2004, com a criação do Grupo de Apoio aos Arranjos Produtivos Locais (GTPAPL), no âmbito do Ministério do Desenvolvimento, Indústria e Comércio Exterior (MDIC).

7 Suzigan e Furtado (2010) mostram essa fragilidade no contexto da implementação de políticas industriais no Brasil no período recente.

8 Conferir dados da Tabela 2, que mostra que o estado de Mato Grosso do Sul é, dentre os analisados neste trabalho, aquele que conta com o maior número de APLs apoiados (95) e com o maior percentual de arranjos de origem agroindustrial (68). A maior parte destes arranjos é apoiada pelo Banco do Brasil, através da estratégia DRS

9 Ver os trabalhos de Costa e Andrade (2008) e Ferreira Jr. et al (2008) para uma análise da implementação dos programas com o BID no Pará e na Bahia, respectivamente. Ver também Cassiolato, Lastres e Stallivieri (2008), para uma análise da evolução institucional da política de apoio à APLs no Brasil e de algumas experiências estaduais.

\section{Ana Lúcia Tatsch}

\section{Economista}

Doutora em Economia pela Universidade Federal do Rio de Janeiro

Professora do Departamento de Economia e Relações Internacionais da Universidade Federal do rio Grande do Sul (UFRGS) e Pesquisadora Associada à Rede de Pesquisa em Sistemas e Arranjos Produtivos e Inovativos Locais (RedeSist). E-mail: analuciatatsch@gmail.com 
Marisa dos Reis A. Botelho

Economista

Doutora em Economia pela Universidade Estadual de Campinas.

Professora do Programa de Pós-graduação em Economia do Instituto de Economia da Universidade Federal de Uberlândia (UFU) e Pesquisadora associada à Rede de Pesquisa em Sistemas e Arranjos Produtivos e Inovativos Locais (RedeSist) da Universidade Federal do Rio de Janeiro (UFRJ)

E-mail: botelhomr@ufu.br

\section{Universidade Federal do Rio Grande do Sul (UFRGS)}

Av. Paulo Gama, 110 - Farroupilha, Porto Alegre - Rio Grande do Sul

CEP: 90040-060

\section{Universidade Federal do Rio de Janeiro (UFRJ)}

Av. Pedro Calmon, 550 - Cidade Universitária, Rio de Janeiro

CEP: 21941-901

\section{Universidade Federal de Uberlândia (UFU)}

Av. João Naves de Ávila 2121 - Campus Santa Mônica CX 593 - Uberlândia - MG - CEP 38408-100 